\title{
Unstoppable force
}

\section{After 40 years in development, and some $\$ 650$ million of NASA funds, Gravity Probe B is almost ready to launch. Would Einstein, whose theories it is about to test, have approved? Tony Reichhardt reports.}


Charmed life: three times during the twisting saga of Gravity Probe B's construction, NASA has tried unsuccessfully to pull the plug on the project.

$\Lambda$ t first glance, the saga of Gravity Probe B looks like a success story. Plucky scientists and engineers have spent four decades - most of their working lives fighting technical and political battles, beating huge odds to reach the launch pad at long last. It is the longest-running development project in NASA's history. Some observers think it's a colossal waste of money, and the space agency has tried to cancel the mission at least three times. But the US Congress has always restored its funding, and despite yet another setback on the launch pad this month, the probe is now set to make a triumphant launch in the first half of next year.

Even the critics have to acknowledge Gravity Probe B's technical brilliance and the sheer gutsiness of its engineering. It will use the most perfect gyroscopes ever built to make one of the most sensitive measurements in the history of physics. As it passes from pole to pole in its 640-kilometre-high orbit, it will test two key predictions of Einstein's general theory of relativity: that a massive body such as Earth warps the fabric of space-time, and that it drags space-time around with it as it rotates. Neither prediction has been proved experimentally, at least not to Gravity Probe B's level of precision. And if by chance the experiment throws up a surprise, it could have profound consequences for physics.
So why, just a few months ago, was NASA's head of space science so frustrated that he threatened, not for the first time, to kill the project?

\section{Heavenly vision}

First, some history. Gravity Probe B dates from 1960, when physicist Leonard Schiff and colleagues at Stanford University proposed an experiment that would exploit advances in gyroscope technology to look for evidence of 'frame-dragging. They pictured an orbiting telescope holding its gaze on a target star while four almost perfect gyroscopes spin alongside the instrument, their axes all oriented in the same direction. If frame-dragging were to tug at the gyroscopes as Einstein predicted, their axes would shift ever so slightly over the course of a year, allowing physicists to measure the phenomenon with a precision of $1 \%$ or better.

By 1964, NASA was providing low-level funding for the project. Perfect quartz spheres had to be fashioned and electrically suspended at the heart of each gyroscope so that they could spin freely in a vacuum. The design would require an ultra-cold container filled with superfluid helium, and ultra-gentle thrusters to manoeuvre the spacecraft everything on Gravity Probe B had to be 'ultra'. Within 20 years, the technology had pro- gressed enough for NASA to fund a test flight, bringing the project's price tag to $\$ 130$ million, not counting the shuttle's launch costs.

By the late 1980s, however, NASA was reeling from the Challenger accident, money was tight, and the agency was increasingly relying on 'decadal reviews' by the National Academy of Sciences to set funding priorities. An expensive gravitational physics experiment was not high on many people's agenda. Even today, would Gravity Probe B survive a peerreviewed competition with other space experiments in its price bracket? "Probably not," says Eugene Parker, a University of Chicago astrophysicist who kept faith with the project when chairing a review of it in 1991.

NASA cancelled Gravity Probe B in 1989. It cancelled it again in 1993, and again in 1995. But no one had counted on the political skill of Francis Everitt, the Stanford physicist who has been the project's principal investigator since 1981. Everitt was relentless in his lobbying, says one congressional staffer, targeting everyone from politicians representing his home state of California to members of federal appropriations committees. It worked. Every time NASA tried to pull the plug, the Congress resurrected the project.

Meanwhile, the probe's price tag kept growing. This was partly due to technical setbacks, but Stanford project managers also 


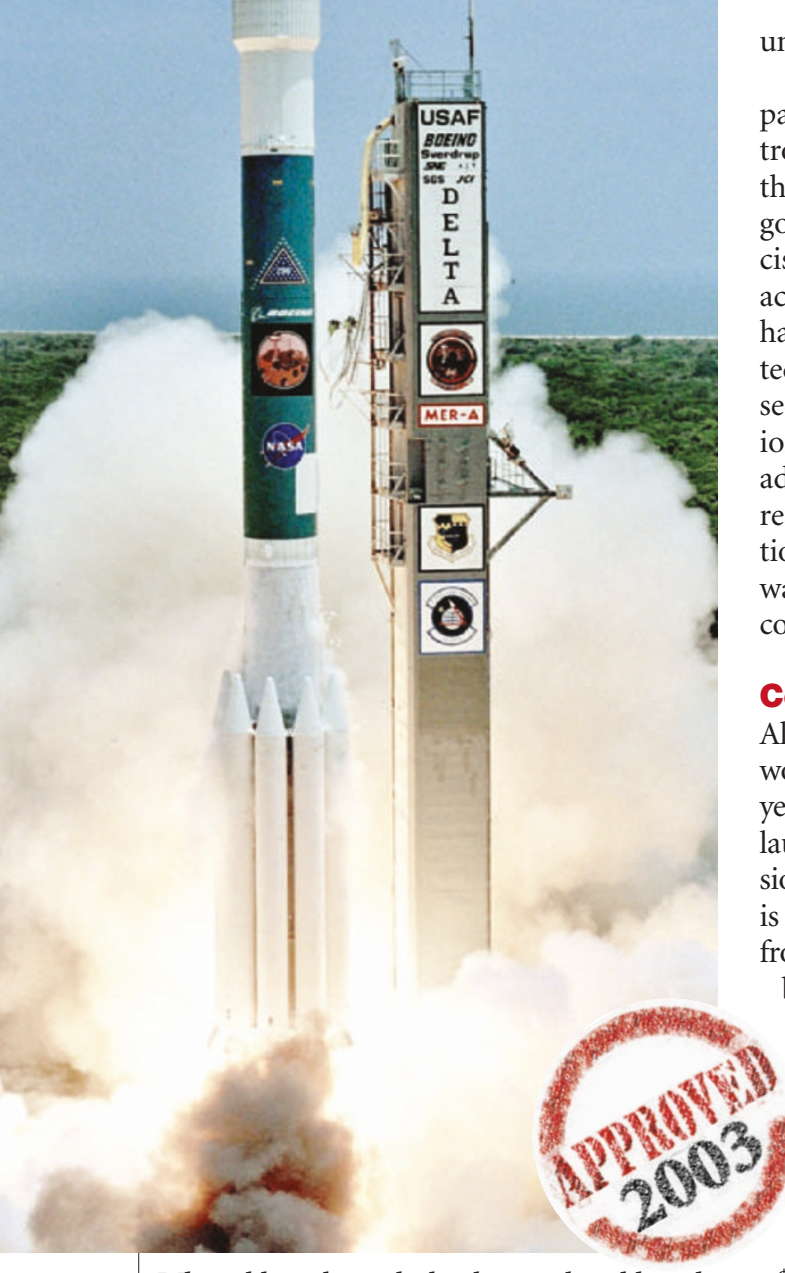

What a blast: the probe has beaten the odds and is set to launch next year on a Delta II rocket.

complained that NASA was not providing enough cash to allow them to overcome problems without disrupting the schedule. For various reasons, the launch date kept slipping, and by this year the cost had ballooned to $\$ 650$ million.

Meanwhile, the study's scientific rationale became less compelling. Astronomers using the Rossi X-Ray Timing Explorer found indirect evidence of frame-dragging around a black hole in 1997, and a year later researchers reported a rough measurement of framedragging by Earth. This result, accurate only to within $20 \%$, was based on data from the LAGEOS geodetic satellites, which are reflective spheres stationed in Earth's orbit - simple stuff by Gravity Probe B's exacting standards. But future LAGEOS studies may cut the margin of error to $5 \%$, prompting the latest review of Gravity Probe B to admit "some erosion" in its scientific value in recent years.

After the Probe failed a ground test late last year (a minor problem caused by blown fuses, say its managers), an exasperated Ed Weiler, NASA's chief of space science, ordered yet another external review of the project's scientific merit and technical readiness. "I have no idea when and if it will ever be launched," Weiler complained at an academy meeting last March. He issued a threat to cancel the project unless it passed the reviews. Once again, it did.

Over the years, the reviews have followed a pattern: acknowledge that the project is controversial and technically challenging, and then conclude - cautiously - that it should go ahead anyway. Val Fitch, a Princeton physicist and Nobel laureate who chaired the 1995 academy review, says that as so much money had already been spent on it, and its biggest technical hurdles had been overcome, it seemed wrong not to continue. But that opinion "was not unanimous by any means", he adds. Few on the panel thought that the results would deviate from Einstein's predictions, leading opponents to argue that there was no point in going ahead if the results could be predicted with such confidence.

\section{Cost concerns}

All that is now in the past. Even Weiler, who would gladly have killed Gravity Probe B years ago, says: "I look forward to a successful launch and a successful mission." His main concern now is preventing other projects from running so horribly over budget. It's about jumping on problems before it becomes impossible to turn back, he argues. "I'd much rather cancel a programme when we've spent a million dollars than when we've spent $\$ 400$ million," he says.

This new-found discipline is apparent in projects such as the Messenger mission to Mercury, scheduled for launch next May. When Messenger, which is part of NASA's Discovery Program of planetary missions and is managed by the Johns Hopkins University Applied Physics Laboratory, ran $\$ 12$ million over its \$300-million budget, Weiler considered cancelling it outright.

Instead, he asked his advi-

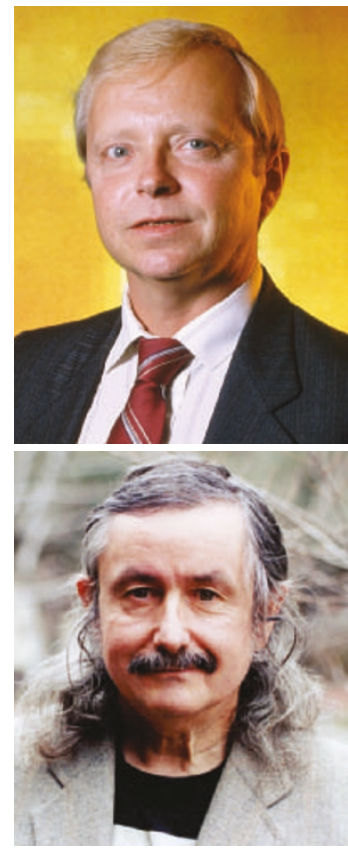

Political powers: Ed Weiler (top) and Francis Everitt. nological development and cost assessment, earlier in their journey to the launch pad.

Being aware of budget creep is one thing, but controlling it is another - particularly as NASA's projects become more technically difficult. "We have done the easy Discovery missions already," says Weiler. Pessimistic observers see a disaster looming, with an expensive effort to develop nuclear propulsion under way, the Mars Exploration Program overextended to the point that an ambitious 2009 Mars Rover mission already appears underfunded, and many smaller projects struggling to stay on time and on budget. Juggling all of these projects will be difficult, and some will almost inevitably be cancelled.

The European Space Agency, faced with similar problems but a smaller science budget, recently cast off ballast of its own. In response to "an outlook with no budget increase or other relief”, the agency's Science Program Committee scrapped the proposed Eddington mission to search for planets outside our Solar System and study the Sun's interior, and sacrificed the planned lander from its BepiColombo mission to explore Mercury.

Gravity Probe B will not be among NASA's cancellations. Weiler can take solace in the fact that, with the struggle nearly over, the mission will not eat up much more money. And who knows, maybe the science will equal the technical feats, and Gravity Probe B will discover something truly new.

"I've got my fingers crossed," says Eugene Parker, a veteran of the Gravity Probe B debate. He understands criticism of the project, but thinks it's a justified, even necessary, check of general relativity. Cosmology is taking off in many directions, from dark energy to string theory, all depending to some extent on Einstein's equasory council whether Messenger's scientific tions. Before heading deeper into unexplored mission was valuable enough to allow it to territory, Parker says, "it would be nice to be expand slightly beyond its original cost. The absolutely sure, or surer than we are at present, council was not thrilled to be asked that question, Weiler says, because a 'yes' answer meant delaying funding for the next Discovery mission. Messenger was saved, but not without a stern warning to the scientific community on the importance of fiscal discipline.

Weiler says that NASA, too, has learned that its technical oversight must be beefed up to catch potential problems earlier. Discovery projects will be required to increase their budget reserve from $20 \%$ to $25 \%$ - meaning that, as Weiler admits, "there might be a little less science". And large projects, such as the successor to the Hubble Space Telescope (see Nature 422,$3 ; 2003$ ), will spend more money on tech- of the general form of those equations".

Einstein didn'thave to wait as long as NASA for his ideas to be tested. As early as 1919, astronomers measured the deflection of starlight during a solar eclipse - confirming a key prediction of general relativity. It is unlikely that Einstein had any doubt, however. In response to the news that his friend and fellow physicist Max Planck stayed up all night during the 1919 eclipse to see if it would confirm relativity, he said: "If he had really understood [the theory], he would have gone to bed the way I did." The chances are that Einstein would have stayed in bed for Gravity Probe B too.

Tony Reichhardt writes for Nature from Washington DC. 